Document downloaded from:

http://hdl.handle.net/10251/71077

This paper must be cited as:

Luz Minguez, I.; Leon Peris, A.; Boronat Zaragoza, M.; Llabrés I Xamena, FX.; Corma Canós, A. (2013). Selective aerobic oxidation of activated alkanes with MOFs and their use for epoxidation of olefins with oxygen in a tandem reaction. Catalysis Science and Technology. 3:371-379. doi:10.1039/C2CY20449E.

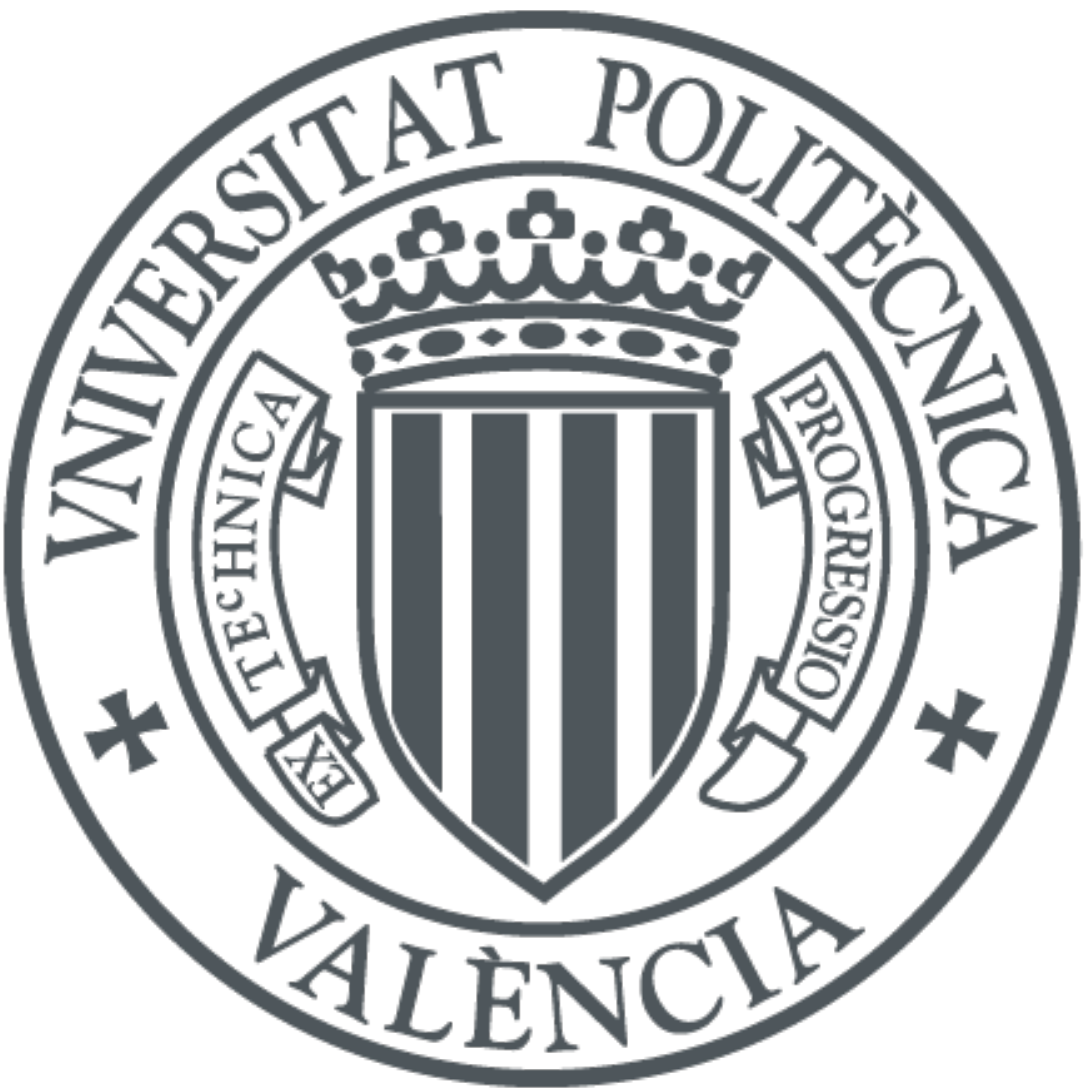

The final publication is available at

http://dx.doi.org/10.1039/c2cy20449e

Copyright Royal Society of Chemistry

Additional Information 


\title{
Selective aerobic oxidation of activated alkanes with MOFs and their use for epoxidation of olefins with oxygen in a tandem reaction
}

\section{Luz, A. León, M. Boronat, F. X. Llabrés i Xamena* and A. Corma*}

Instituto de Tecnología Química UPV-CSIC, Universidad Politécncia de Valencia, Consejo Superior de Investigaciones Científicas, Avda. de los Naranjos s/n, 46022 Valencia, Spain

*Corresponding authors: e-mails: fllabres@itq.upv.es, acorma@itq.upv.es

Fax: (+34) 963877809

\begin{abstract}
MOFs with $\mathrm{Cu}^{2+}$ centers linked to four nitrogen atoms from azaheterocyclic compounds, i.e., pyrimidine $\left[\mathrm{Cu}(2 \text {-pymo })_{2}\right]$ and imidazole $\left[\mathrm{Cu}(\mathrm{im})_{2}\right]$, are active catalysts for aerobic oxidation of activated alkanes, such as tetralin, cumene and ethylbenzene. Differences in activity among the two MOFs appear to be related with differences in their ability to decompose the hydroperoxide and to coordinate to the resulting radical $\cdot \mathrm{OH}$ species. Copper ions in $\left[\mathrm{Cu}(\mathrm{im})_{2}\right]$ can coordinate by expanding their coordination sphere from 4 to 5 in a reversible way, while in the case of $[\mathrm{Cu}(2-$ pymo $)_{2}$ ] it results in a displacement of one of the pyrimidine ligands. The MOFs can be used in combination with a silylated Ti-MCM-41 to catalyze the epoxidation of olefins with oxygen by means of a tandem reaction in where the MOF produces cumene hydroperoxide, that is used by Ti-MCM-41 to epoxidize the olefin.
\end{abstract}

\section{Introduction}

There is much interest in the design of hybrid materials for selective and multi-step catalytic processes ${ }^{1}$. In this field, Metal-Organic Frameworks (MOFs) can play an important role due to the possibility to control and fine tune the crystalline structure, porosity, chemical environment and functionalities of the material. Compared to purely inorganic porous materials, MOFs offer in general higher flexibility for the design of 
the catalytic center ${ }^{2-4}$, which makes them interesting materials for heterogeneous catalysis, provided that mild reaction conditions are required. In this way, it is possible to design MOF-based heterogeneous catalysts in which the active sites are located either at the metallic sites or at the organic linkers, or even associated to catalytic species bonded or entrapped inside the pore system of the MOF ${ }^{5,6}$. Moreover, this large flexibility can readily lead to the design of multi-functional MOF catalysts ${ }^{7,8}$ by combining two or more types of active centers in the same material, such as metalmetal, metal-acid, metal-base or acid-base functionalities.

We have recently reported ${ }^{9}$ that a copper-containing MOF, $\left[\mathrm{Cu}(2-\text { pymo })_{2}\right]$ (2-pymo $=2$-oxypyrimidinolate,${ }^{10}$ ) could be of interest as heterogeneous catalyst for the liquidphase oxidation of tetralin $(\mathrm{T}-\mathrm{H})$ using air as oxidant. Under the reactions conditions studied, a relatively high T-H conversion ( $\mathrm{ca} .52 \%)$ was attained without affecting the crystalline structure of the solid, which allowed to reuse the MOF without important loss of activity ${ }^{9}$. However, this $\mathrm{Cu}-\mathrm{MOF}$ showed some limitations. The most important was the high level of tetralinhydroperoxide $(\mathrm{T}-\mathrm{OOH})$ accumulated at the beginning of the reaction (up to $24 \mathrm{~mol} \%$ yield) and a low selectivity to the ketone, $\alpha$-tetralone $(\mathrm{T}=\mathrm{O})$. We found that this inconvenience can be avoided by physically mixing $[\mathrm{Cu}(2-$ pymo $)_{2}$ ] with another MOF, i.e., cobalt benzimidazole ZIF-9 ${ }^{11}$, that react the hydroperoxides.

In the present work, we have extended our studies on the aerobic oxidation of tetralin to a copper-containing $\mathrm{MOF},\left[\mathrm{Cu}(\mathrm{im})_{2}\right]\left(\mathrm{im}=\right.$ imidazolate, $\left.{ }^{12}\right)$, which has a chemical composition and crystalline structure related to that of $\left[\mathrm{Cu}(2-\text { pymo })_{2}\right]$. Recently, we have successfully used both materials for coupling reactions; viz. 1,3-dipolar cycloadditions of azides to alkynes ${ }^{13}$, and three-component coupling of aldehydes, amines and terminal alkynes ${ }^{14}$. In the present work, we have found that $\left[\mathrm{Cu}(\mathrm{im})_{2}\right]$ has a better catalytic performance as compared to $\left[\mathrm{Cu}(2-\text { pymo })_{2}\right]$ for tetralin oxidation, in terms of activity, maximum T-H conversion and selectivity to the ketone. At the same time, $\left[\mathrm{Cu}(\mathrm{im})_{2}\right]$ produces less $\mathrm{T}-\mathrm{OOH}$ accumulation in the reaction medium than $[\mathrm{Cu}(2-$ pymo $)_{2}$ ] under the same conditions, avoiding the use of a second MOF to deal with the hydroperoxides. Therefore, $\left[\mathrm{Cu}(\mathrm{im})_{2}\right]$ largely overcomes the limitations of the previously reported $\left[\mathrm{Cu}(2-\text { pymo })_{2}\right]$ as a catalyst for aerobic tetralin oxidation, with no need to prepare physical mixtures with a second catalyst. Besides tetralin, we have also studied the aerobic oxidation of other substrates; viz., cumene and ethylbenzene, which let us make an evaluation of the potential of both $\left[\mathrm{Cu}(2 \text {-pymo })_{2}\right]$ and $\left[\mathrm{Cu}(\mathrm{im})_{2}\right]$ as 
catalysts for the oxidation of benzilic paraffins. Since both MOFs were active for such oxidations we have attempted a cascade reaction. Then, we will also show that, when $\left[\mathrm{Cu}(2-\text { pymo })_{2}\right]$ is combined with a second solid catalyst (silylated Ti-MCM-41), the in situ generated hydroperoxide can be used to transform an olefin into the corresponding epoxide with good selectivity and acceptable yield. A comparison will be made between the performance of this mixed catalytic system under different working setups (i.e., onepot and two-pot setups).

\section{Materials and methods}

\subsection{Preparation of the $\mathrm{Cu}-\mathrm{MOF}$}

The $\mathrm{Cu}-\mathrm{MOFs}$ were prepared according to the corresponding procedures reported in the original references for $\left[\mathrm{Cu}(2 \text {-pymo })_{2}\right]^{10}$ and $\left[\mathrm{Cu}(\mathrm{im})_{2}\right]^{12}$. X-ray diffraction (Phillips $\mathrm{X}$ 'Pert, $\mathrm{Cu} \mathrm{K \alpha}$ radiation) was used to confirm the expected crystalline structure of the materials.

\subsection{Silylated Ti-MCM-41}

Silylated Ti-MCM-41 was prepared following the original procedure ${ }^{15}$. First, Ti-MCM41 was obtained from a gel having the following molar composition: $\mathrm{SiO}_{2}: 0.015$ Ti(OEt) $)_{4}: \quad 0.26$ CTABr: $\quad 0.26$ TMAOH: $24.3 \quad \mathrm{H}_{2} \mathrm{O}$ where $\mathrm{CTABr}$ is cetyltrimethylammonium bromide and $\mathrm{TMAOH}$ is tetramethylammonium hydroxide. The silica source, Aerosil-200, was obtained from Degussa. The crystallization was performed at $100{ }^{\circ} \mathrm{C}$ for $48 \mathrm{~h}$ in Teflon lined stainless steel autoclaves. The occluded surfactant was completely removed following a two step extraction procedure. TiMCM-41 was then fully silylated with hexamethyldisilazane (HMDS) as the silylating agent. The silylation was carried out at $120{ }^{\circ} \mathrm{C}$ with a solution of HMDS in toluene under inert atmosphere. The MCM-41 structure was preserved after silylation and the surface area of the silylated sample was close to $1000 \mathrm{~m}^{2} \mathrm{~g}^{-1}$.

\subsection{Computational details}

Calculations were carried out by means of the Gaussian03 program package ${ }^{16}$ using the density functional B3PW91 method ${ }^{17,18}$ and the standard 6-311G(d,p) basis set ${ }^{19}$. The $\mathrm{Cu}$ active sites in $\left[\mathrm{Cu}(\mathrm{im})_{2}\right]$ and $\left[\mathrm{Cu}(2 \text {-pymo })_{2}\right]$ MOFs were modeled by means of two clusters of atoms consisting of a central $\mathrm{Cu}^{2+}$ cation surrounded by either four imidazole or four 2-hydroxypyrimidine molecules. Each of the four organic ligands in the resulting models was saturated with a proton placed in the direction of the next $\mathrm{Cu}^{2+}$ cation in the real MOF material, so that each model bears a net positive charge of +2 , 
and the geometry of the two cluster models was fully optimized without any restriction. For the complexes formed by interaction of the $\mathrm{Cu}^{2+}$ sites with $\mathrm{CM}-\mathrm{OOH}$, with CM-O. radical and with a $\cdot \mathrm{OH}$ radical, two types of geometry optimizations were performed: i) a restricted optimization, in which the positions of the four terminal hydrogen atoms saturating the organic ligands were kept fixed to model the partial flexibility of the MOF material, and ii) a full optimization in which the positions of all atoms in the system were allowed to relax without any restriction. Calculations were performed with different spin states of the central copper atom for all models, and the singlet state was found the most stable in all cases. Finally, thermal corrected Gibbs free energies at 298 K were obtained from vibrational frequency calculations at the same B3PW91/6$311 \mathrm{G}(\mathrm{d}, \mathrm{p})$ level of theory.

\subsection{Catalytic reactions}

Liquid phase oxidation. Liquid phase aerobic oxidation of tetralin, cumene and ethylbenzene were carried out in two-necked flask reactors with the amount of catalysts to obtain an alkane/metal molar ratio of 2000 (for tetralin) or 200 (for cumene and ethylbenzene). The system was heated at either $90^{\circ} \mathrm{C}$ (for tetralin) or $80^{\circ} \mathrm{C}$ (for cumene and ethylbenzene) and air was fed into the reactor by bubbling at a constant rate (0.5 $\mathrm{mL} / \mathrm{s}$ ) by means of an adjustable valve. A reflux system with PEG at $0 \circ \mathrm{C}$ was installed, so that vapours were condensed, being the total mass balances $99 \pm 1 \%$. After each catalytic test, the solid catalyst was recovered by filtration and thoroughly washed with acetone and dried in an oven at $60^{\circ} \mathrm{C}$ overnight. The crystallinity of the used catalyst was confirmed by X-ray diffraction comparing with the fresh material spectra. Time evolution of products was determined by GC analysis of the samples (Varian 3900, capillary column HP-5) using $n$-hexadecane as external standard. The intermediate hydroperoxides formed ( $\mathrm{T}-\mathrm{OOH}, \mathrm{CM}-\mathrm{OOH}$ and $\mathrm{EB}-\mathrm{OOH})$ were quantitatively determined by means of an indirect method using triphenylphosphine (TPP) ${ }^{20}$. Preliminary experiments were performed to find the conditions in where the reaction is not controlled by external diffusion. Then, three experiments were performed at stirring rates of 500, 1000 and $1500 \mathrm{rpm}$. No differences in the initial reaction rate were observed, indicating that for stirring speeds of $500 \mathrm{rpm}$ the reaction is not controlled by external diffusion. Therefore, the experiments have always been performed at $500 \mathrm{rpm}$. 
Tandem cumene oxidation and 1-octene epoxidation. $1 \mathrm{ml}$ of cumene and $1 \mathrm{ml}$ of 1 octene were placed in a $10 \mathrm{ml}$ pressured tubular reactor. A solid mixture of $5 \mathrm{mg}$ of $\left[\mathrm{Cu}(2-\text { pymo })_{2}\right]$ and $2.5 \mathrm{mg}$ of sylilated Ti-MCM-41 $\left(2.1 \mathrm{wt} \% \mathrm{TiO}_{2}\right){ }^{15}$ were added to the solution and the reactor was pressured at 3 bar with air. The reaction was carried out at two control temperatures: $333 \mathrm{~K}$ and $363 \mathrm{~K}$

\section{Results and discussion}

\subsection{Liquid phase oxidation of tetralin}

Oxidation of tetralin to the corresponding ketone, $\alpha$-tetralone, is interesting for the preparation of a number of chemicals (insecticides, agrochemicals and drugs) and for the production of oxygenated diesel molecules ${ }^{21}$. This reaction can be performed using air as the oxidant and in the presence of a suitable oxidation catalyst, yielding a mixture of tetralinhydroperoxide $(\mathrm{T}-\mathrm{OOH}), \alpha$-tetralol $(\mathrm{T}-\mathrm{OH})$ and $\alpha$-tetralone $(\mathrm{T}=\mathrm{O})$, as depicted in Scheme 1:

[Scheme 1 near here]

As we have shown in a previous work ${ }^{9}$, the copper-containing MOF $\left[\mathrm{Cu}(2-\text { pymo })_{2}\right]$ is an active and reusable catalyst for the liquid phase oxidation of $\mathrm{T}-\mathrm{H}$ using air as the oxidant. A maximum T-H conversion of about $52 \%$ was achieved after $48 \mathrm{~h}$ of reaction at $90{ }^{\circ} \mathrm{C}$, with a $\mathrm{T}-\mathrm{H} /$ metal molar ratio of 2000 . Conversely, when the reaction was carried out in the presence of $\left[\mathrm{Cu}(\mathrm{im})_{2}\right]$, keeping all the other reaction conditions unchanged, the maximum amount of $\mathrm{T}-\mathrm{H}$ converted increased up to $68 \%$, and this value was reached after only $22 \mathrm{~h}$ of reaction. A comparison of the two catalysts for the oxidation of $\mathrm{T}-\mathrm{H}$ can be seen in Figure 1 and Table $1 .\left[\mathrm{Cu}(\mathrm{im})_{2}\right]$ also showed a higher activity than $\left[\mathrm{Cu}(2 \text {-pymo })_{2}\right]$, being turnover frequencies (TOF) calculated from the initial reaction rates from Figure 119000 and $4000 \mathrm{~h}^{-1}$ for $\left[\mathrm{Cu}(\mathrm{im})_{2}\right]$ and $[\mathrm{Cu}(2-$ pymo $\left.)_{2}\right]$, respectively. Thus, for instance, after $8 \mathrm{~h}$ of reaction, the conversion of T-H over $\left[\mathrm{Cu}(2 \text {-pymo })_{2}\right]$ was only $18 \%$, while the conversion over $\left[\mathrm{Cu}(\mathrm{im})_{2}\right]$ already reached $55 \%$. Blank experiments performed in the absence of any MOF catalyst (i.e., autothermal oxidation) gave very poor conversions, attaining a maximum $\mathrm{T}-\mathrm{H}$ conversion of $1.3 \mathrm{~mol} \%$ after $24 \mathrm{~h}$ (see Table 1), being $\mathrm{T}-\mathrm{OOH}$ the only product formed.

[Figure 1 near here] 
[Table 1 near here]

Another important parameter of the oxidation reaction is the final selectivity to the ketone, which is usually expressed as the molar ratio of $\alpha$-tetralone to $\alpha$-tetralol, $\mathrm{T}=\mathrm{O} / \mathrm{T}-\mathrm{OH}$. As it can be seen in Table 1, also from this point of view the performance of $\left[\mathrm{Cu}(\mathrm{im})_{2}\right]$ is better than $\left[\mathrm{Cu}(2-\text { pymo })_{2}\right]$ : the values of $\mathrm{T}=\mathrm{O} / \mathrm{T}-\mathrm{OH}$ calculated at maximum conversion were 3.5 and 2.7 for $\left[\mathrm{Cu}(\mathrm{im})_{2}\right]$ and $[\mathrm{Cu})_{2}$-pymo $\left.)_{2}\right]$, respectively. Finally, as we mentioned above, the use of [Cu(2-pymo)2] as catalyst for $\mathrm{T}-\mathrm{H}$ oxidation showed an undesired accumulation of hydroperoxides in the reaction medium, which reaches up to $24 \%$ of the initial amount of $\mathrm{T}-\mathrm{H}$ after $18 \mathrm{~h}$. The presence of large quantities of the hydroperoxide during the reaction can be a safety hazard, so must be avoided. On the contrary, when $\left[\mathrm{Cu}(\mathrm{im})_{2}\right]$ was used as catalyst, the concentration of $\mathrm{T}$ $\mathrm{OOH}$ was kept much lower during all the reaction, reaching a maximum concentration of only $9 \mathrm{~mol} \%$ at short reaction time (1 h) and dropping below 1-2 mol\% shortly afterwards (see Figure 1b).

In summary, as we have shown in Figure 1 and Table 1 , the use of $\left[\mathrm{Cu}(\mathrm{im})_{2}\right]$ as catalyst for the liquid phase aerobic oxidation of T-H presents a number of benefits with respect to $\left[\mathrm{Cu}(2 \text {-pymo })_{2}\right]$ which makes it a very interesting material for this reaction. We also observed that both catalysts were stable under the experimental conditions used, since the materials recovered after the catalytic reaction showed XRD patterns practically undistinguishable from those of the fresh materials. The occurrence of copper leaching from the framework was also ruled out by a hot filtration test and by chemical analysis of the filtrate after removing the solid catalyst at the end of the reaction. Stability and leaching tests were already reported and discussed in detail for $\left[\mathrm{Cu}(2 \text {-pymo })_{2}\right]$ in our previous work ${ }^{9}$, so they are not reproduced again here, being the results obtained with $\left[\mathrm{Cu}(\mathrm{im})_{2}\right]$ completely analogous.

Encouraged by the good results obtained with $\left[\mathrm{Cu}(\mathrm{im})_{2}\right]$ for $\mathrm{T}-\mathrm{H}$ oxidation, we extended our studies to other substrates: cumene and ethylbenzene. We wanted, on one hand to determine the general applicability of these copper-containing MOFs as catalysts for paraffin oxidation. And if the result were positive, we thought on designing a multistep catalytic process in where the cumene hydroperoxide formed could further react, as oxidizing agent, for the synthesis of epoxides from olefins.

\subsection{Liquid phase oxidation of cumene}


Oxidation of cumene $(\mathrm{CM})$ with air yields cumene hydroperoxide $(\mathrm{CM}-\mathrm{OOH})$ in the first place, which is then converted into cumene alcohol $(\mathrm{CM}-\mathrm{OH})$, usually accompanied by other byproducts (mainly acetophenone, AP) coming from nonselective decomposition side reactions ${ }^{22}$. Figure 2 and Table 1 show a comparison of the results obtained for the liquid phase aerobic oxidation of cumene $\left(80{ }^{\circ} \mathrm{C}, 0.5 \mathrm{~mol} \%\right.$ $\mathrm{Cu})$ using either $\left[\mathrm{Cu}(2 \text {-pymo })_{2}\right]$ or $\left[\mathrm{Cu}(\mathrm{im})_{2}\right]$ as catalyst.

[Figure 2 near here]

The results obtained for cumene oxidation are qualitatively very similar to those obtained for the oxidation of $\mathrm{T}-\mathrm{H}$, which demonstrates that both $\mathrm{Cu}-\mathrm{MOF}$ are able to catalyze this reaction. As occurred before for $\mathrm{T}-\mathrm{H}$, the imidazolate material $\left[\mathrm{Cu}(\mathrm{im})_{2}\right]$ also shows a better oxidation performance as compared to [Cu(2-pymo $)_{2}$, although the differences observed between the two catalysts are less pronounced than in the oxidation of T-H. Complete CM conversion was achieved after $23 \mathrm{~h}$ over $\left[\mathrm{Cu}(\mathrm{im})_{2}\right]$, while some lower conversion (i.e., 87\%) was obtained with $\left[\mathrm{Cu}(2-\text { pymo })_{2}\right]$. The selectivity towards $\mathrm{CM}-\mathrm{OH}$ was also higher in the case of $\left[\mathrm{Cu}(\mathrm{im})_{2}\right](74 \%$, versus $64 \%$ obtained for $\left[\mathrm{Cu}\left(2-\mathrm{pymo}_{2}\right]\right)$. In both cases, at the end of the reaction the sole product observed besides $\mathrm{CM}-\mathrm{OH}$ was acetophenone, which accounted for the rest of $\mathrm{CM}$ converted (25\% and 23\%, respectively). It can also be observed in Figure 2 that the amount of accumulated $\mathrm{CM}-\mathrm{OOH}$ is higher (and lasts longer) in the case of $[\mathrm{Cu}(2-$ pymo) 2 ] (up to $24 \% \mathrm{CM}-\mathrm{OOH}$ after $8 \mathrm{~h}$, see Table 1 , entry 4 ). However, the activity of both materials is practically the same at short reaction times (up to $2 \mathrm{~h}$ ), as evidenced by the superposition of both curves in Figure 2a. From the slopes of the time-conversion curves at short reaction times, a TOF of about $3500 \mathrm{~h}^{-1}$ was calculated for both copper catalysts. Blank experiment in the absence of catalyst yielded $21 \% \mathrm{CM}-\mathrm{OOH}$ and $3 \%$ AP after $24 \mathrm{~h}$ (see Table 1).

\subsection{Ethylbenzene oxidation}

Oxidation of ethylbenze is expected to be more difficult than in the case of tetralin or cumene, since the carbon atom to be oxidized is less activated. In the case of ethylbenzene, oxygen is added onto a secondary carbon atom, while in cumene the preferred position for the attack is on a tertiary carbon atom, which allows a major stabilization of the radical species formed. In tetralin the addition of oxygen is onto a 
secondary carbon atom, but in this case, it belongs to a six-member ring, which adds an extra activation as compared to ethylbenzene.

Although the conversion of ethylbenzene was considerably lower than that observed for cumene under similar conditions (at $80{ }^{\circ} \mathrm{C}, 0.5 \mathrm{~mol} \% \mathrm{Cu}$ ), both $\left[\mathrm{Cu}(2-\mathrm{pymo})_{2}\right]$ and $\left[\mathrm{Cu}(\mathrm{im})_{2}\right]$ demonstrated to be active catalysts for this reaction, as shown in Figure 3. In this case, $\left[\mathrm{Cu}(\mathrm{im})_{2}\right]$ showed a better performance at short reaction time, although at the end of the reaction the two materials gave similar results: $29 \%$ (25\%) conversion after $40 \mathrm{~h}$ and $86 \%(87 \%)$ selectivity to acetophenone for $\left[\mathrm{Cu}(\mathrm{im})_{2}\right]$ and for $\left[\mathrm{Cu}(2-\mathrm{pymo})_{2}\right]$, respectively.

[Figure 3 near here]

If we compare the kinetic data obtained for EB oxidation (Figure 3) with the data obtained for TH and CM oxidation (Figures 1 and 2), clear differences can be observed. On one hand, accumulation of hydroperoxide in the reaction medium does not occur during EB oxidation, not even when $\left[\mathrm{Cu}(2-\text { pymo })_{2}\right]$ was used as catalyst. This is not surprising, since the hydroperoxyde derived from ethylbenzene is the least stable among all the substrates studied in this work. Thus, when 1-phenylhydroperoxide (EB-OOH) is generated, it is immediately converted into other products (i.e., acetophenone and 1phenylethanol). On the other hand, we also observed clear induction periods of about 2$3 \mathrm{~h}$, in which EB is not converted, irrespective of the catalyst used. Both observations indicate that in the EB oxidation reaction, formation of the hydroperoxide species is difficult for both $\mathrm{Cu}-\mathrm{MOF}$ catalysts. However, once this primary species is formed, it is converted to reaction products more effectively over $\left[\mathrm{Cu}(\mathrm{im})_{2}\right]$ than over $[\mathrm{Cu}(2-$ pymo $)_{2}$ ]. Blank experiment in the absence of catalyst yielded only $2 \% \mathrm{~EB}-\mathrm{OH}$ and $0.5 \%$ EB-OOH after $24 \mathrm{~h}$ (see Table 1).

\subsection{Origin of the different reactivities of $\left[\mathrm{Cu}(2-\mathrm{pymo})_{2}\right]$ and $\left[\mathrm{Cu}(\mathrm{im})_{2}\right]$}

In light of the results presented above, and which are summarized in Table 1, it is evident that $\left[\mathrm{Cu}(\mathrm{im})_{2}\right]$ is a better catalyst than $\left[\mathrm{Cu}(2-\mathrm{pymo})_{2}\right]$ for the oxidation of $\mathrm{TH}$, $\mathrm{CM}$ and EB. In general, we have observed that both, formation of the primary hydroperoxide species and its conversion into final products is faster for the imidazolate compound. Both compounds feature $\mathrm{Cu}^{2+}$ ions coordinated to four $\mathrm{N}$ atoms from different diazaheteorcyclic compounds (imidazole and pyrimidine), thus leading to 
$\mathrm{CuN}_{4}$ centers. However, $\mathrm{Cu}^{2+}$ ions are in square planar coordination in $\left[\mathrm{Cu}(2-\text { pymo })_{2}\right]$, while they are in a highly distorted coordination in $\left[\mathrm{Cu}(\mathrm{im})_{2}\right]$, with trans $\mathrm{N}-\mathrm{Cu}-\mathrm{N}$ angles of $140^{\circ}$ and $155^{\circ}$. In a first approximation, one can expect that these structural differences could account for the different reactivity observed for both materials. However, it is difficult for us to explain intuitively the structure-composition-reactivity correlation for the two $\mathrm{Cu}^{2+}$ MOFs studied. Then, and in order to get more insights into the structural and electronic properties of the two compounds, we have carried out first principle DFT calculations on MOF model clusters, as described in detail in the Experimental section. The models used consisted of a central $\mathrm{Cu}^{2+}$ ion surrounded by either four imidazole (im) or four 2-hydroxypyrimidine (2-pymo) molecules. Each of the four organic ligands in the cluster models was saturated with a proton placed in the direction of the next $\mathrm{Cu}^{2+}$ ion in the real MOF material, so that each model bears a net positive charge of +2 . The geometry of the two resulting clusters was fully optimized without restrictions.

To bring some light on the different catalytic behavior of the two copper-containing MOFs $\left[\mathrm{Cu}(\mathrm{im})_{2}\right]$ and $\left[\mathrm{Cu}(2-\text { pymo })_{2}\right]$, we have theoretically investigated using DFT the interaction of these two materials with cumene-hydroperoxide (CM-OOH) to form an adsorption complex $\left[\mathrm{Cu}^{2+}-\mathrm{HOO}-\mathrm{CM}\right]$, and its subsequent dissociation into a hydroxyl radical that remains adsorbed on the copper center $\left[\mathrm{Cu}^{2+}-\mathrm{OH}\right]$ and a free cumyl $(\cdot \mathrm{O}-\mathrm{CM})$ radical. The fully optimized structures (see Computational details) resulting from $\mathrm{CM}-\mathrm{OOH}$ adsorption on the two $\mathrm{Cu}^{2+}$ active site models are depicted in Figure 4. $\mathrm{CM}-\mathrm{OOH}$ adsorption was found to be energetically favorable on the two materials studied, with calculated free energy values of $-6 \mathrm{kcal} / \mathrm{mol}$ for $\left[\mathrm{Cu}(\mathrm{im})_{2}\right]$ and $-2 \mathrm{kcal} / \mathrm{mol}$ for $\left[\mathrm{Cu}(2 \text {-pymo })_{2}\right]$, irrespectively of the type of geometry optimization performed (full or restricted). The optimized $\mathrm{Cu}^{2+}-\mathrm{O}$ distances found were 2.47 and $2.30 \AA$ in $\left[\mathrm{Cu}(\mathrm{im})_{2}\right]$ and $\left[\mathrm{Cu}(2 \text {-pymo })_{2}\right]$ materials, respectively, also indicating a certain degree of interaction. It is worth noting that the initial geometry of the active center in both MOFs is not significantly distorted in any case as a consequence of the interaction with the hydroperoxide. However, after cumene hydroperoxide dissociation, substantial differences were found in the resulting $\left[\mathrm{Cu}^{2+}-\mathrm{OH}\right]$ complexes formed in the two materials. On one hand, $\mathrm{Cu}^{2+}$ ions in $\left[\mathrm{Cu}(\mathrm{im})_{2}\right]$ were found to expand their coordination sphere from 4 to 5 upon binding of a $\cdot \mathrm{OH}$ radical. On the contrary, the interaction of the - $\mathrm{OH}$ radical with the $\mathrm{Cu}^{2+}$ centre in $\left[\mathrm{Cu}(2-\text { pymo })_{2}\right]$ implies the de-coordination of one of the four 2-pymo ligands. Note that this ligand displacement would not necessary imply 
the collapse of the crystalline structure of the MOF. Actually, the $\mathrm{Cu}^{2+}$ centers would still remain connected to the framework through three out of the four initial 2-pymo ligands. Once the catalytic cycle is finished and the product desorbs from the active site, the 2-pymo ligand that has been displaced can coordinate again to the $\mathrm{Cu}^{2+}$ site to recover the initial catalytic centre, as shown in Scheme 2. A similar ligand displacement and re-coordination cycle has been demonstrated to occur in a series of zinc(II) benzoate coordination polymers during transesterification reactions ${ }^{23}$.

[Figure 4 near here]

[Scheme 2 near here]

In conclusion, the results obtained from first principle calculations indicate that $\left[\mathrm{Cu}(\mathrm{im})_{2}\right]$ has a more adaptable crystalline framework than $\left[\mathrm{Cu}(2-\text { pymo })_{2}\right]$, which allows that the copper sites expand their coordination sphere from 4 to 5 upon interaction with $\cdot \mathrm{OH}$ radical species. On the contrary, binding of the same radical to $\left[\mathrm{Cu}(2 \text {-pymo })_{2}\right]$ produces the displacement of one of the 2-pymo ligands from the coordination sphere around the central $\mathrm{Cu}$ site. These differences could account for the higher activity of $\left[\mathrm{Cu}(\mathrm{im})_{2}\right]$ to decompose the hydroperoxyde into final products, and at the same time could explain the experimentally observed accumulation of the $\mathrm{CM}-\mathrm{OOH}$ intermediate in the oxidation of $\mathrm{CM}$ catalyzed by $\left[\mathrm{Cu}(2-\text { pymo })_{2}\right]$. Even if this preliminary computational study does not include calculation of the transition states corresponding to the two $\mathrm{Cu}-\mathrm{MOF}$, it is not unreasonable to expect that a higher energy would be required in the case of $\left[\mathrm{Cu}(2-\text { pymo })_{2}\right]$ to break a $\mathrm{Cu}$-pyrimidine bond that in the case of $\left[\mathrm{Cu}(\mathrm{im})_{2}\right]$ in which only a rearrangement of the ligands is required to accommodate the $\cdot \mathrm{OH}$ radical.

Nevertheles, in order to demonstrate that the two MOFs have indeed different abilities for decomposing the hydroperoxyde, we have designed an additional experiment. Thus, when we contacted the two MOFs with cumene hydroperoxide, it was observed that $\left[\mathrm{Cu}(\mathrm{im})_{2}\right]$ decomposes the hydroperoxide significatively faster than $\left[\mathrm{Cu}(2-\mathrm{pymo})_{2}\right]$ under identical conditions $(0.01 \mathrm{mmol} \mathrm{Cu}, 0.9 \mathrm{~mL} \mathrm{CM}, 0.1 \mathrm{~mL} \mathrm{CM}-$ $\mathrm{OOH}, 80^{\circ} \mathrm{C}$ under $\mathrm{N}_{2}$ atmosphere). After 1 hour, $\left[\mathrm{Cu}(\mathrm{im})_{2}\right]$ decomposed $55 \mathrm{~mol} \%$ of the initial CM-OOH, while only $31 \mathrm{~mol} \%$ was decomposed over [Cu(2-pymo $\left.)_{2}\right]$. 


\subsection{Tandem Cumene oxidation and 1-octene epoxidation using a combination of catalysts: One-pot versus two-pot setups}

As we have mentioned above, one of the drawbacks of [Cu(2-pymo $\left.)_{2}\right]$ as oxidation catalyst is that a considerable amount of hydroperoxide is accumulated in the reaction medium, especially in the case of cumene and tetralin oxidation. This limitation can be turned into an advantage if we are able to use the hydroperoxide generated in situ during the oxidation as a reagent for a second reaction. This becomes even more interesting if one can couple the two reactions in a one-pot process, thus leading to a tandem catalytic process. Taking as a source of inspiration the Sumitomo process ${ }^{24,} 25$ for olefin epoxidation using cumene hydroperoxide, we have combined $\left[\mathrm{Cu}(2-\text { pymo })_{2}\right]$ with a state-of-the-art epoxidation catalyst (silylated Ti-MCM-41 ${ }^{15}$ ) to perform the tandem process depicted in Scheme 3. The experimental setup is shown in Fig. 5a. Thus, $[\mathrm{Cu}(2-$ pymo $)_{2}$ ] is used in the first reaction to oxidize $\mathrm{CM}$ into $\mathrm{CM}-\mathrm{OOH}$ using air as the oxidant (reaction R1). Then, silylated Ti-MCM-41 can use the generated $\mathrm{CM}-\mathrm{OOH}$ to oxidize an olefin (1-octene) in reaction $\mathrm{R} 2$, producing 1-octene oxide and one equivalent of $\mathrm{CM}-\mathrm{OH}$.

[Scheme 3 near here]

[Figure 5 near here]

However, this simple reaction scheme is complicated by the occurrence of competing unwanted side reactions, which decrease the overall selectivity to 1-octene oxide by either yielding secondary products of 1-octene (SR2 and/or SR3), or by spuriously consuming $\mathrm{CM}-\mathrm{OOH}$ without transferring the oxygen to 1-octene (SR1). Side reaction SR1 consists in the decomposition of the $\mathrm{CM}-\mathrm{OOH}$ into $\mathrm{CM}-\mathrm{OH}$ and AP. This reaction is catalyzed by $\left[\mathrm{Cu}(2-\text { pymo })_{2}\right]$, as we have already demonstrated in the previous section, and it can also take place thermically (non catalytic decomposition). SR2 consists in the direct allylic oxidation/isomerization of 1-octene, to produce a mixture of oxidized products. SR2 can also be catalyzed by copper or an uncatalyzed thermal reaction. Finally SR3, consisting in the ring opening of the epoxide, is another reaction that in principle could decrease the overall yield of 1-octene oxide.

After a preliminary screening of different conditions, we found a satisfactory experimental setup, as detailed in the experimental section. Among others, the following parameters were considered: i) $\left[\mathrm{Cu}(2-\mathrm{pymo})_{2}\right]$ to silylated Ti-MCM-41 ratio; 
ii) cumene to 1-octene ratio; iii) temperature of the reaction; iv) order of addition of the reagents; and v) oxygen pressure. To evaluate the relevance of the different competing side reactions, we carried out the oxidation process at two different temperatures, viz. 333 and $363 \mathrm{~K}$. A summary of the results obtained is shown in Table 2.

[Table 2 near here]

When the reaction was performed at $333 \mathrm{~K}$, an overall conversion of 1-octene of 7.1 mol\% was achieved after $48 \mathrm{~h}$, producing 1-octene oxide with a selectivity of $63.4 \%$, together with other products coming from the allylic oxidation of 1-octene. In a separate experiment we have observed that pure $\left[\mathrm{Cu}(2-\text { pymo })_{2}\right]$ can indeed catalyze the allylic oxidation of 1-octene using air as the oxidant, yielding mainly the products indicated in Scheme 3 (12\% maximum conversion of 1-octene achieved after $24 \mathrm{~h}$ at $363 \mathrm{~K}$ ). Note that these oxidation products can also be formed through a non-catalyzed thermal reaction. It is important to stress that in our system we did not detect any traces of products coming from ring aperture of the formed epoxide (SR3), which is largely suppressed by the hydrophobic character of the silylated Ti-MCM-41 catalyst used and the absence of water in the reaction medium ${ }^{15}$.

When the reaction temperature was increased to $363 \mathrm{~K}$, the overall reaction rate dramatically increased: $17.1 \%$ 1-octene conversion after $24 \mathrm{~h}$ was observed, which represents an almost 5-fold increase of the reaction rate. Interestingly, the selectivity to 1-octene oxide was practically the same (63.2\%), with a similar distribution of secondary products than at lower temperature.

Another important parameter of the tandem reaction is given by the $\mathrm{CM}-\mathrm{OH} / \mathrm{epoxide}$ ratio, which reveals the extent to which the competing side reaction SR1 is taking place. Indeed, if all the $\mathrm{CM}-\mathrm{OOH}$ formed in $\mathrm{R} 1$ is used to produce 1-octene oxide following $\mathrm{R} 2$, the final CM-OH/epoxide ratio should be equal to 1 . Any excess amount of $\mathrm{CM}-\mathrm{OH}$ with respect to 1-octene oxide (as well as the presence of acetophenone in the products mixture) indicates that $\mathrm{CM}-\mathrm{OOH}$ has been spuriously decomposed without producing the desired epoxide. This is an important factor to take into account, since in the envisaged reaction scheme the $\mathrm{CM}-\mathrm{OH}$ produced has to be recovered and reconverted into $\mathrm{CM}$ (through a dehydration and hydrogenation process) for recycling. If we compare our results obtained at 333 and $363 \mathrm{~K}$, we can see that at the lower temperature, although the reaction rate is considerable low, the process is highly 
selective concerning the utilization of the $\mathrm{CM}-\mathrm{OOH}$ formed $(\mathrm{CM}-\mathrm{OH} /$ epoxide $=1.1)$. On the contrary, upon increasing the temperature of the reaction, the alternative SR1 side reaction becomes the main reaction pathway for $\mathrm{CM}-\mathrm{OOH}$ decomposition (CM$\mathrm{OH} /$ epoxide $=3.0$ ). Thus, an increase of the reaction temperature has negative effects on the amount of $\mathrm{CM}-\mathrm{OH}$ waste generated per mol of final product.

One evident limitation of this one-pot setup is the relatively low selectivity to the epoxide (63.2\% at $363 \mathrm{~K}$ ), which is due, as mentioned above, to the occurrence of the competing side-reaction SR2: allylic oxidation of 1-octene catalyzed by [Cu(2-pymo $\left.)_{2}\right]$. The only way of suppressing this reaction, thus increasing the selectivity to the epoxide product, is to avoid the contact between 1-octene and the copper-MOF by keeping them in separate reactors. In other words, it becomes necessary to adopt a two-pot setup, such as that shown in Fig. 5b. In such a reaction setup, $\left[\mathrm{Cu}(2-\text { pymo })_{2}\right]$ is allowed to interact with $\mathrm{CM}$ under an $\mathrm{O}_{2}$ atmosphere at $363 \mathrm{~K}$ for $4 \mathrm{~h}$, to produce $\mathrm{CM}-\mathrm{OOH}$ in $24 \mathrm{~mol} \%$ yield (see Fig. 5b). Then, the copper-catalyst is removed by filtration and the liquid filtrate is fed into a second reactor, containing silylated Ti-MCM-41, and 1-octene is added at this point. Under these conditions, 1-octene was selectively converted into the corresponding epoxide, yielding $18.1 \mathrm{~mol} \%$ after $24 \mathrm{~h}$ at $363 \mathrm{~K}$. In this case, no traces of products coming from either the allylic oxidation of 1-octene, or from the ringopening of the epoxide, were detected. A final $\mathrm{CM}-\mathrm{OH} / \mathrm{epoxide}$ ratio of 3.0 was obtained. Note that most of this $\mathrm{CM}-\mathrm{OH}$ was already present in the filtrate coming from the first reactor (38 mol\%, see Fig. 5b). Indeed, $\mathrm{CM}-\mathrm{OOH}$ is used to oxidize the olefin in the second reactor with a high selectivity $(24 \mathrm{~mol} \% \mathrm{CM}-\mathrm{OOH}$ produce $18.1 \mathrm{~mol} \%$ of 1-octene oxide), while direct decomposition of the hydroperoxide occurs only to a minor extent in the second reactor. This is largely prevented by the absence of the copper catalyst at this stage (which would catalyze the side reaction SR1) and to the relatively low temperature (which minimize the autocatalytic thermal decomposition of $\mathrm{CM}-\mathrm{OOH})$.

\section{Conclusion}

In this work, we have shown that copper-containing MOFs in which $\mathrm{Cu}^{2+}$ centers are linked to 4 nitrogen atoms from azaheterocyclic compounds (i.e., pyrimidine and imidazole) have interesting potential as heterogeneous catalysts for aerobic liquid phase oxidation of activated paraffins. We have shown this for two materials, $\left[\mathrm{Cu}(\mathrm{im})_{2}\right]$ and $\left[\mathrm{Cu}(2-\text { pymo })_{2}\right]$ and for three different substrates of increasing demands: tetralin, cumene 
and ethylbenzene. Our results indicate that $\left[\mathrm{Cu}(\mathrm{im})_{2}\right]$ has in general better performance than $\left[\mathrm{Cu}(2 \text {-pymo })_{2}\right]$, which results in higher alkane conversion, higher selectivity and low accumulation of alkylhydroperoxides in the reaction medium. According to DFT calculations, the differences between the two catalysts could be related with the different ability of the two MOFs to decompose the hydroperoxyde and to coordinate to the resulting radical $\cdot \mathrm{OH}$ species. Copper ions in $\left[\mathrm{Cu}(\mathrm{im})_{2}\right]$ can coordinate to these radicals by expanding their coordination sphere from 4 to 5 . On the contrary, in the

case of $\left[\mathrm{Cu}(2-\text { pymo })_{2}\right]$, coordination of a radical species to the $\mathrm{Cu}^{2+}$ ions results in the displacement of one of the pyrimidine ligands. This different behavior of the two MOFs also explains why the $\mathrm{ROOH}$ intermediate is accumulated in the reaction medium when $\left[\mathrm{Cu}(2 \text {-pymo })_{2}\right]$ is used as catalyst, and not in the case of $\left[\mathrm{Cu}(\mathrm{im})_{2}\right]$.

We have also shown that the hydroperoxyde accumulated in the reaction medium when $\left[\mathrm{Cu}(2-\text { pymo })_{2}\right]$ is used as catalyst can be used as oxidant in a parallel reaction. To illustrate this, we have combined $\left[\mathrm{Cu}(2-\text { pymo })_{2}\right]$ with a good epoxidation catalyst (silylated Ti-MCM-41) to carry out a tandem process consisting in cumene oxidation and 1-octene epoxidation. We have studied this reaction using either a one-pot or a twopot setup. A main drawback of the one-pot setup is that $\left[\mathrm{Cu}(2-\text { pymo })_{2}\right]$ can also catalyze the allylic oxidation of 1-octene, thus decreasing the net epoxide yield. To overcome this problem, it is necessary to avoid he contact between the copper MOF and the olefin. Thus, it becomes necessary to work in two batch reactors.

\section{Acknowledgements}

Financial support by Ministerio de Educación y Ciencia e Innovación (Project MIYCIN， CSD2009-00050; PROGRAMA CONSOLIDER. INGENIO 2009), Generalidad Valenciana (GV PROMETEO/2008/130) and CSIC (Proyectos Intramurales Especiales 201080I020) is gratefully acknowledged. CSIC and Fundación Bancaja are gratefully acknowledged for a research contract to I.L. AL thanks the ITQ for a postgraduate scholarship.

\section{References}


1. A. Corma, U. Diaz, T. Garcia, G. Sastre and A. Velty, J. Am. Chem. Soc., 2010, 132, 15011-15021.

2. F. X. Llabrés i Xamena, A. Abad, A. Corma and H. Garcia, J. Catal., 2007, 250, 294-298.

3. D. Farrusseng, S. Aguado and C. Pinel, Angew. Chem., Int. Ed., 2009, 48, 7502-7513.

4. J. Y. Lee, O. K. Farha, J. Roberts, K. A. Scheidt, S. T. Nguyen and J. T. Hupp, Chem. Soc. Rev., 2009, 38, 1450-1459.

5. M. Meilikhov, K. Yusenko, D. Esken, S. Turner, G. Van Tendeloo and R. A. Fischer, Eur. J. Inorg. Chem., 2010, 3701-3714.

6. J. Juan-Alcaniz, J. Gascon and F. Kapteijn, J. Mater. Chem., 2012, DOI.: 10.1039/C1032JM15563J

7. Y. Pan, B. Yuan, Y. Li and D. He, Chem. Commun., 2010, 46, 2280-2282.

8. F. Vermoortele, R. Ameloot, A. Vimont, C. Serre and D. E. De Vos, Chem. Commun., 2011, 47, 1521-1523.

9. F. X. Llabrés i Xamena, O. Casanova, R. Galiasso Tailleur, H. Garcia and A. Corma, J. Catal., 2008, 255, 220-227.

10. L. C. Tabares, J. A. R. Navarro and J. M. Salas, J. Am. Chem. Soc., 2001, 123, 383-387.

11. K. S. Park, Z. Ni, A. P. Cote, J. Y. Choi, R. D. Huang, F. J. Uribe-Romo, H. K. Chae, M. O'Keeffe and O. M. Yaghi, Proc. Natl. Acad. Sci. , 2006, 103, 10186-10191.

12. N. Masciocchi, S. Bruni, E. Cariati, F. Cariati, S. Galli and A. Sironi, Inorg. Chem., 2001, 40, 5897-5905.

13. I. Luz, F. X. Llabrés i Xamena and A. Corma, J. Catal., 2010, 276, 134-140.

14. I. Luz, F. X. Llabrés i Xamena and A. Corma, J. Catal., 2012, 285, 285-291.

15. A. Corma, M. E. Domine, J. Gaona, J. L. Jorda, M. T. Navarro, J. Perez-Pariente, F. Rey, B. McCulloch, L. Nemeth and J. Tsuji, Chem. Commun., 1998, 2211-2212.

16. M. J. Frisch, G. W. Trucks and H. B. Schlegel, Gaussian 03, Revision B.04, Gaussian, Inc., Pittsburgh, PA, Editon edn., 2003.

17. J. P. Perdew and Y. Wang, Phys. Rev. B, 1992, 45, 13244-13249.

18. A. D. Becke, J. Chem. Phys., 1993, 98, 5648-5652.

19. P. C. Hariharan and J. A. Pople, Theor. Chim. Acta, 1973, 28, 213-222.

20. M. M. Fares, M. El-Khateeb and K. J. Asali, J. Inorg. Organomet. Polym, 2003, 13, $143-$ 155.

21. G. Y. Tian, D. H. Xia and F. T. Zhan, Energy Fuels, 2004, 18, 49-53.

22. C. Aprile, A. Corma, M. E. Domine, H. Garcia and C. Mitchell, J. Catal., 2009, 264, 44-53.

23. H. Kwak, S. H. Lee, S. H. Kim, Y. M. Lee, B. K. Park, Y. J. Lee, J. Y. Jun, C. Kim, S.-J. Kim and Y. Kim, Polyhedron, 2009, 28, 553-561.

24. J. Tsuji.

25. J. Tsuji, J. Yamamoto, M. Ishino and N. Oku. 


\section{Figure Captions}

Figure 1. Conversion of $\mathrm{T}-\mathrm{H}$ over $\left[\mathrm{Cu}(\mathrm{im})_{2}\right]$ and $\left[\mathrm{Cu}(2-\text { pymo })_{2}\right]$ (part $a$ ). Time conversion of $\mathrm{T}-\mathrm{H}$ and time evolution of products over $\left[\mathrm{Cu}(\mathrm{im})_{2}\right]$ and $\left[\mathrm{Cu}(2-\mathrm{pymo})_{2}\right]$ is also shown in parts $b$ ) and $c$ ), respectively.

Figure 2. Conversion of $\mathrm{CM}$ over $\left[\mathrm{Cu}(\mathrm{im})_{2}\right]$ and $\left[\mathrm{Cu}(2 \text {-pymo })_{2}\right]$ (part $a$ ). Time conversion of $\mathrm{CM}$ and time evolution of products over $\left[\mathrm{Cu}(\mathrm{im})_{2}\right]$ and $\left[\mathrm{Cu}(2-\mathrm{pymo})_{2}\right]$ is also shown in parts $b$ ) and $c$ ), respectively.

Figure 3. Conversion of $\mathrm{EB}$ over $\left[\mathrm{Cu}(\mathrm{im})_{2}\right]$ and $\left[\mathrm{Cu}(2-\text { pymo })_{2}\right]$ (part $a$ ). Time conversion of EB and time evolution of products over $\left[\mathrm{Cu}(\mathrm{im})_{2}\right]$ and $\left[\mathrm{Cu}(2-\mathrm{pymo})_{2}\right]$ is also shown in parts $b$ ) and $c$ ), respectively.

Figure 4. Optimized structures of the complexes formed by interaction of: a) cumenehydroperoxide with $\left[\mathrm{Cu}(\mathrm{im})_{2}\right]$ b) cumene-hydroperoxide with $\left[\mathrm{Cu}(2-\mathrm{pymo})_{2}\right]$ (c) hydroxyl radical with $\left[\mathrm{Cu}(\mathrm{im})_{2}\right]$ and d) cumene-hydroperoxyl radical and $\left[\mathrm{Cu}(\mathrm{im})_{2}\right]$. Carbon, nitrogen, oxygen, hydrogen and copper atoms are grey, blue, red, white and yellow, respectively.

Figure 5. Schematic representation of the one-pot $(a)$ and two-pot setups $(b)$ adopted for the tandem cumene oxidation/1-octene epoxidation reaction. $\mathrm{CM}=$ cumene; $\mathrm{CM}$ $\mathrm{OOH}=$ cumene hydroperoxyde; $\mathrm{AP}=$ acetophenone Epox $=1$-octene oxide

\section{Scheme captions}

Scheme 1. Tetralin (T-H) oxidation reaction, leading to $\alpha$-tetralinhydroperoxyde (T$\mathrm{OOH}), \alpha$-tetralol $(\mathrm{T}-\mathrm{OH})$ and $\alpha$-tetralone $(\mathrm{T}=\mathrm{O})$.

Scheme 2. Ligand displacement and re-coordination of 2-hydroxypyrimidine in $[\mathrm{Cu}(2-$ pymo $)_{2}$ ] upon coordination/release of a radical species. 
Table 1. Selected kinetic data for the aerobic oxidation of various organic substrates over $\left[\mathrm{Cu}(2-\text { pymo })_{2}\right]$ and $\left[\mathrm{Cu}(\mathrm{im})_{2}\right] \mathrm{MOF}$ catalysts.

\section{Tetralin (T-H)}

\begin{tabular}{lcccc} 
& Conv. $8 \mathrm{~h}$ & Conv. $\max$ & $\mathrm{T}=\mathrm{O} / \mathrm{T}-\mathrm{OH}$ & {$[\mathrm{T}-\mathrm{OOH}] \mathrm{max}$} \\
\hline$\left[\mathrm{Cu}(\mathrm{im})_{2}\right]$ & $55 \%$ & $68 \%(22 \mathrm{~h})$ & 3.5 & $9 \%(1 \mathrm{~h})$ \\
{$\left[\mathrm{Cu}(2-\text { pymo })_{2}\right]$} & $18 \%$ & $52 \%(48 \mathrm{~h})$ & 2.7 & $24 \%(18 \mathrm{~h})$ \\
\hline
\end{tabular}

Blank: $\quad 4$ h: $0.2 \%$ T-OOH; 24 h: $1.3 \%$ T-OOH

\section{Cumene (CM)}

\begin{tabular}{llcc} 
& Conv. max & Select. CM-OH & {$[\mathrm{CM}-\mathrm{OOH}] \max$} \\
\hline$\left[\mathrm{Cu}(\mathrm{im})_{2}\right]$ & $99 \%(23 \mathrm{~h})$ & $74 \%$ & $2(1.5 \mathrm{~h})$ \\
{$\left[\mathrm{Cu}(2-\mathrm{pymo})_{2}\right]$} & $87 \%(23 \mathrm{~h})$ & $64 \%$ & $24(8 \mathrm{~h})$ \\
\hline Blank: & 4 h: $0.5 \% \mathrm{CM}-\mathrm{OOH} ; 24 \mathrm{~h}: 21 \% \mathrm{CM}-\mathrm{OOH}+3 \% \mathrm{AP}$
\end{tabular}

Ethylbenzene (EB)

\begin{tabular}{lccc} 
& Conv. 5 h & Conv. max & Select. AP \\
\hline$\left[\mathrm{Cu}(\mathrm{im})_{2}\right]$ & $23 \%$ & $29 \%(40 \mathrm{~h})$ & $86 \%$ \\
{$\left[\mathrm{Cu}(2-\mathrm{pymo})_{2}\right]$} & $6 \%$ & $25 \%(40 \mathrm{~h})$ & $87 \%$ \\
\hline Blank: & 4 h: No conversión; $24 \mathrm{h:} 2 \% \mathrm{~EB}-\mathrm{OH}+0.5 \% \mathrm{~EB}-\mathrm{OOH}$
\end{tabular}

T-H: Tetralin; T-OOH: Tetralinhydroperoxide; T=O: $\alpha$-tetralone; T-OH: $\alpha$-tetralol; CM: Cumene; CM$\mathrm{OOH}$ : cumene hydroperoxide (2-phenyl-2-propylhydroperoxide); $\mathrm{CM}-\mathrm{OH}$ : cumene alcohol (2-phenyl-2propanol); EB: Ethylbenzene; AP: Acetophenone.

Table 2. Summary of the results obtained for the one-pot tandem reaction shown in Scheme 3.

\begin{tabular}{cccccc}
\hline Temp (K) & $\begin{array}{c}\text { Conv./Time } \\
(\mathrm{mol} \% / \mathrm{h})\end{array}$ & $\begin{array}{c}\text { Yield epox } \\
(\mathrm{mol} \%)\end{array}$ & $\begin{array}{c}\text { Yield oxdn. } \\
(\mathrm{mol} \%)\end{array}$ & $\begin{array}{c}\text { Select. epox } \\
(\%)\end{array}$ & CM-OH/epox \\
\hline 333 & $7.1(48)$ & 4.5 & 2.6 & 63.4 & 1.1 \\
363 & $17.1(24)$ & 10.8 & 6.3 & 63.2 & 3.0 \\
\hline
\end{tabular}

epox $=1$-octene oxide; oxdn $=$ products coming from the allylic oxidation of 1-octene. 


\section{Figure 1}

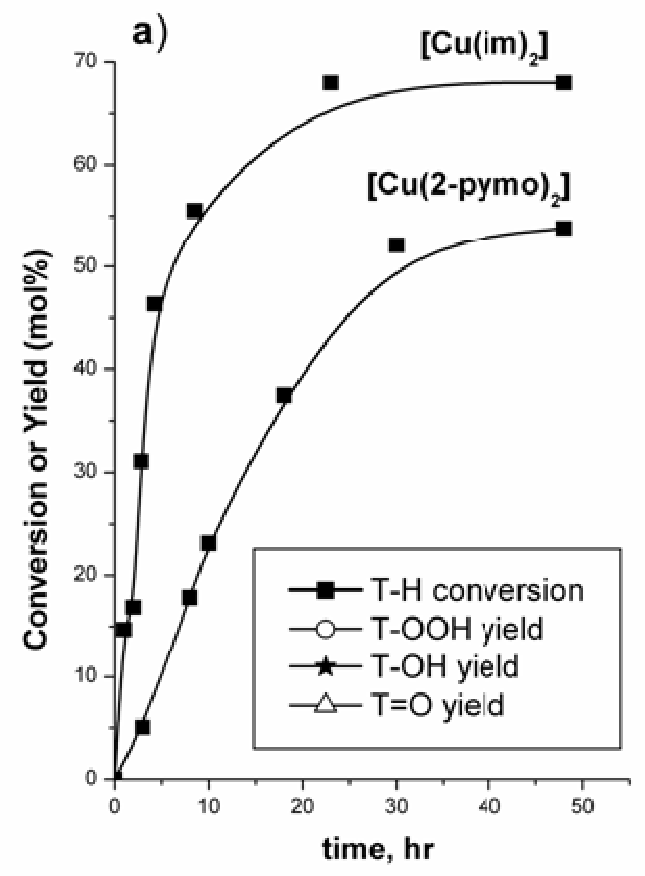

b)
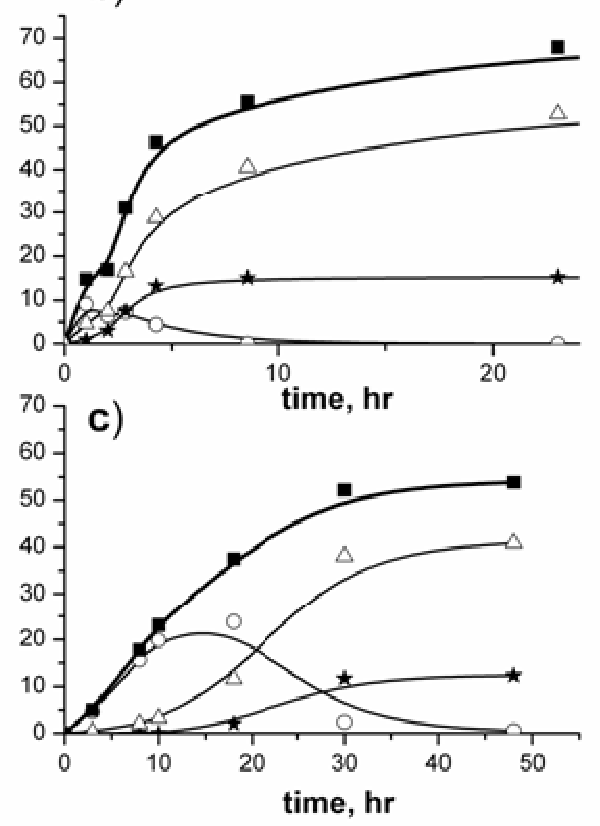

Figure 2

a)

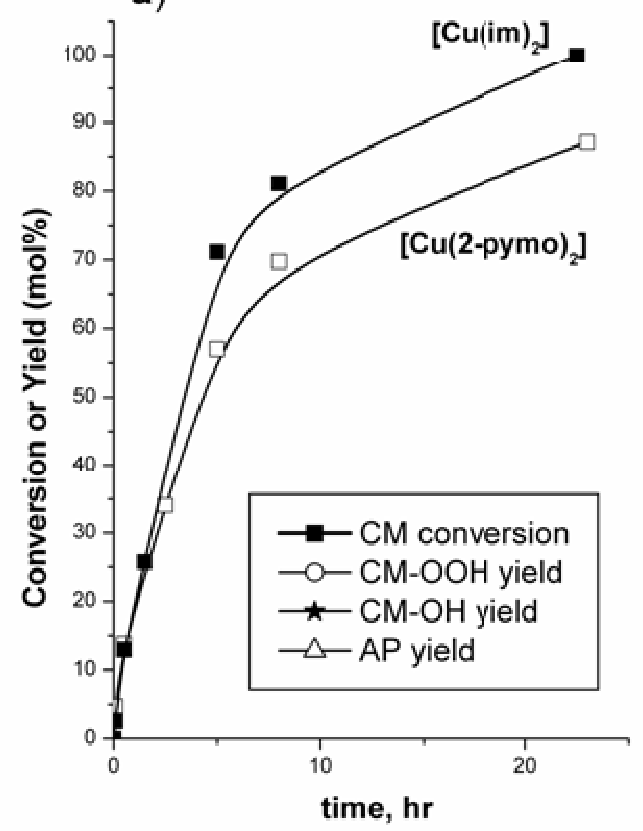

b)

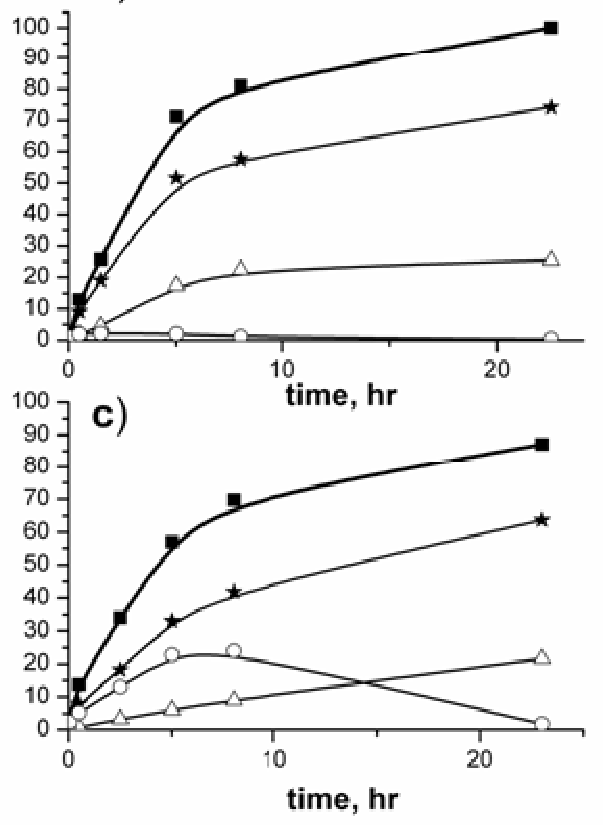


Figure 3

a)

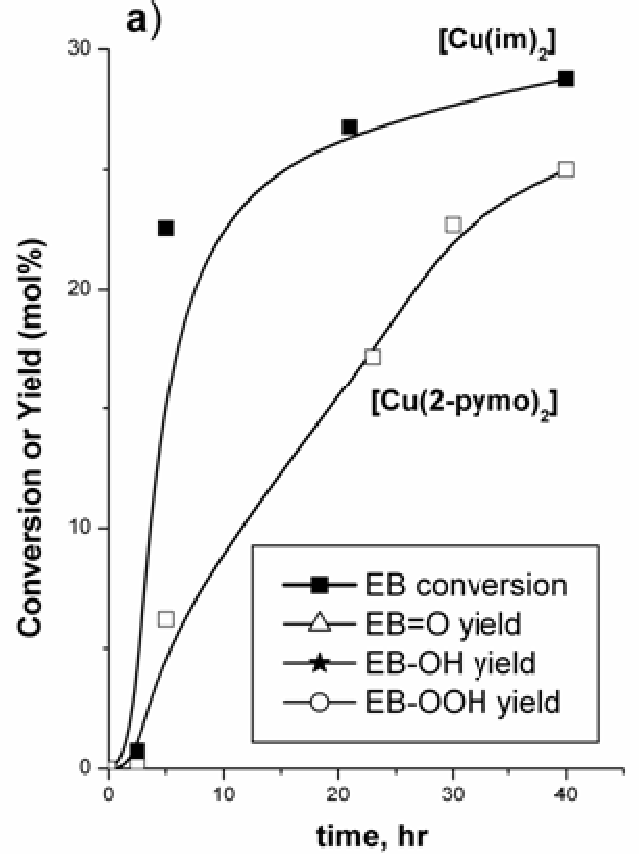

b)
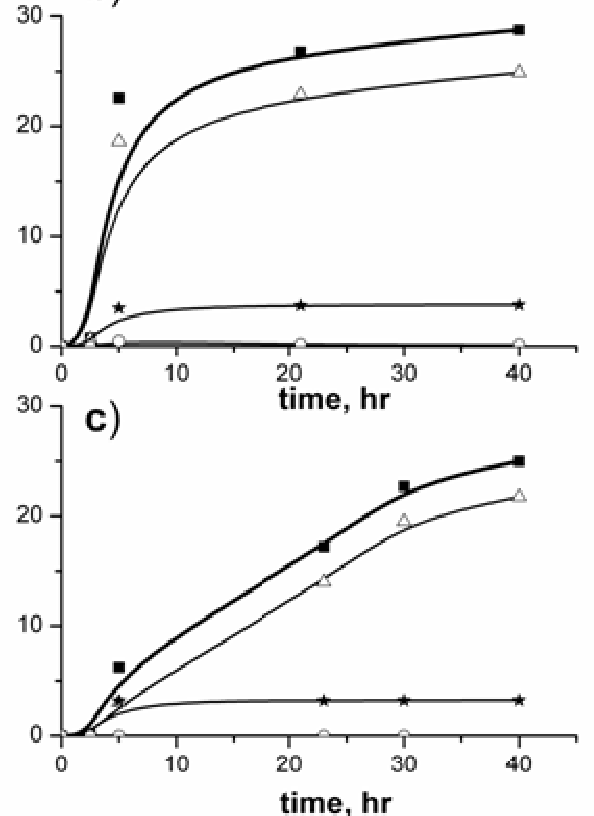
Figure 4

a)

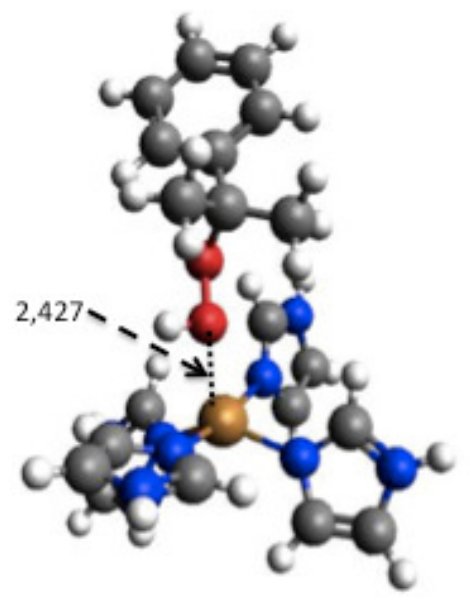

c)

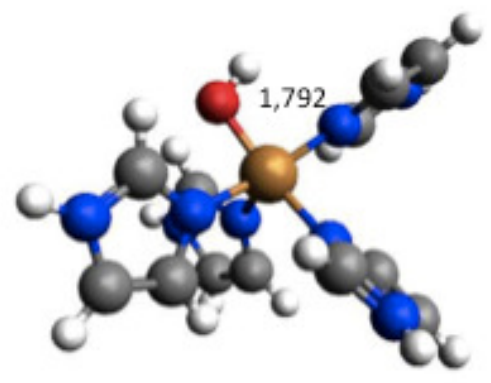

b)

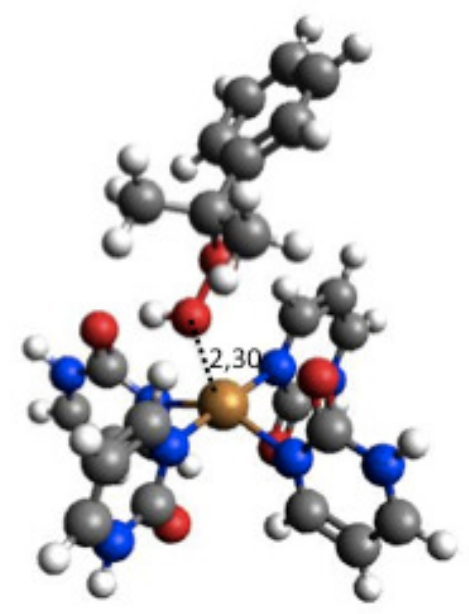

d)

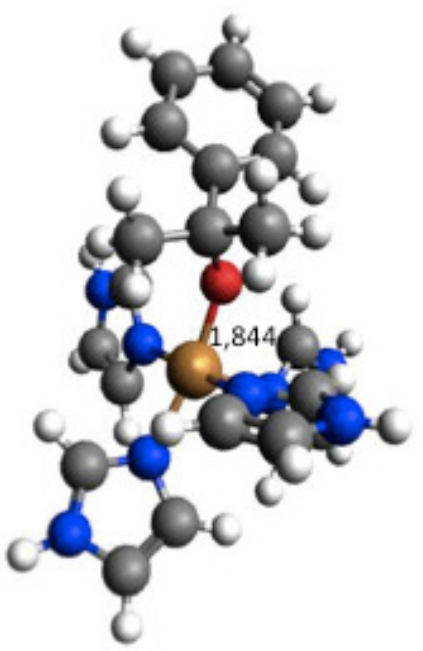


Figure 5

a)

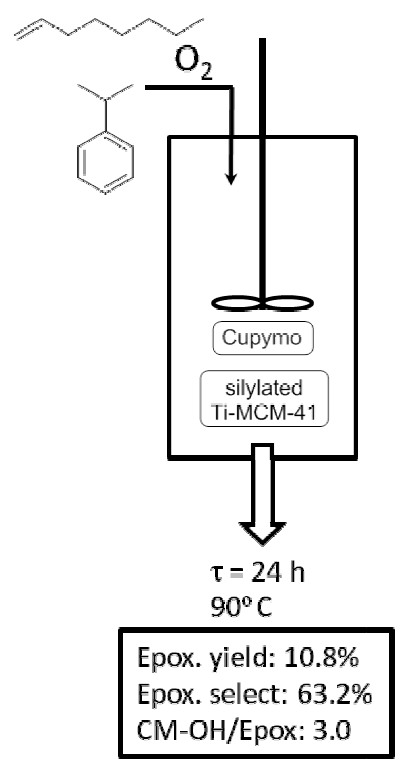

b)

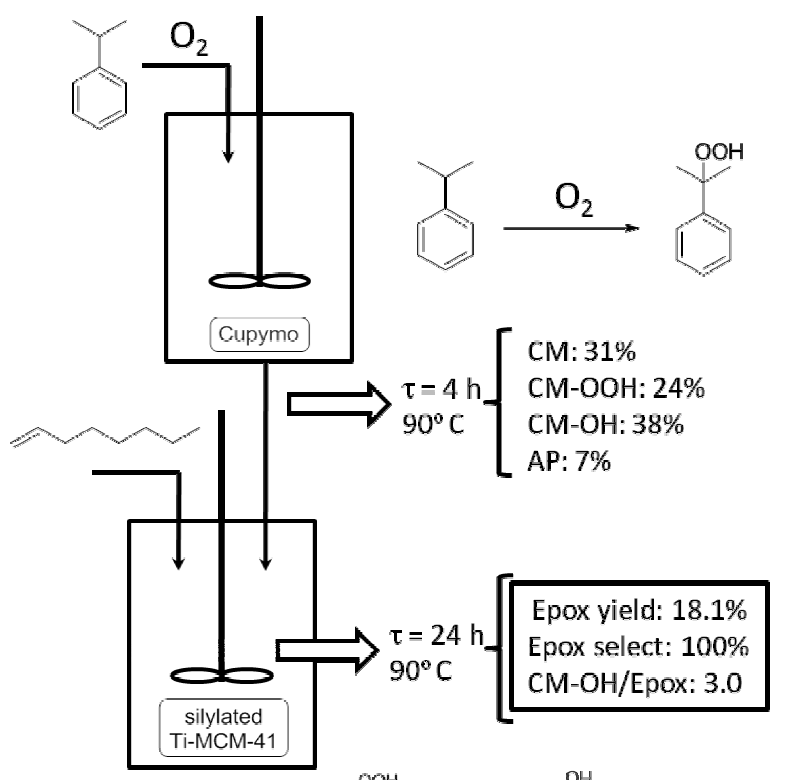

allylic oxidation 
Scheme 1

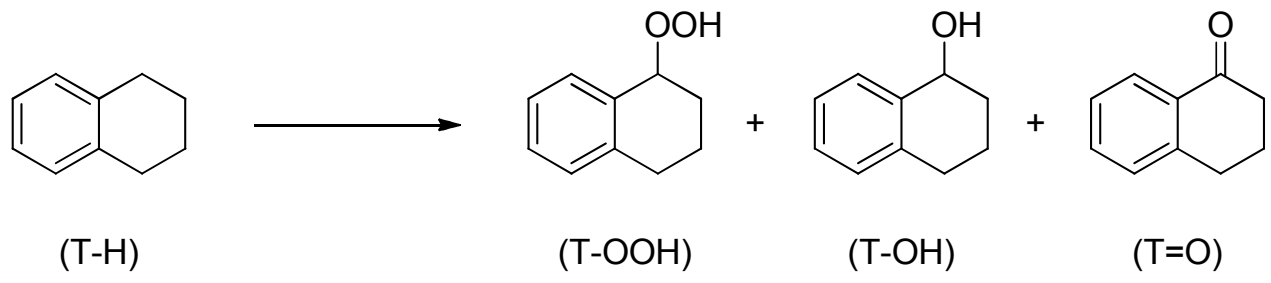

Scheme 2

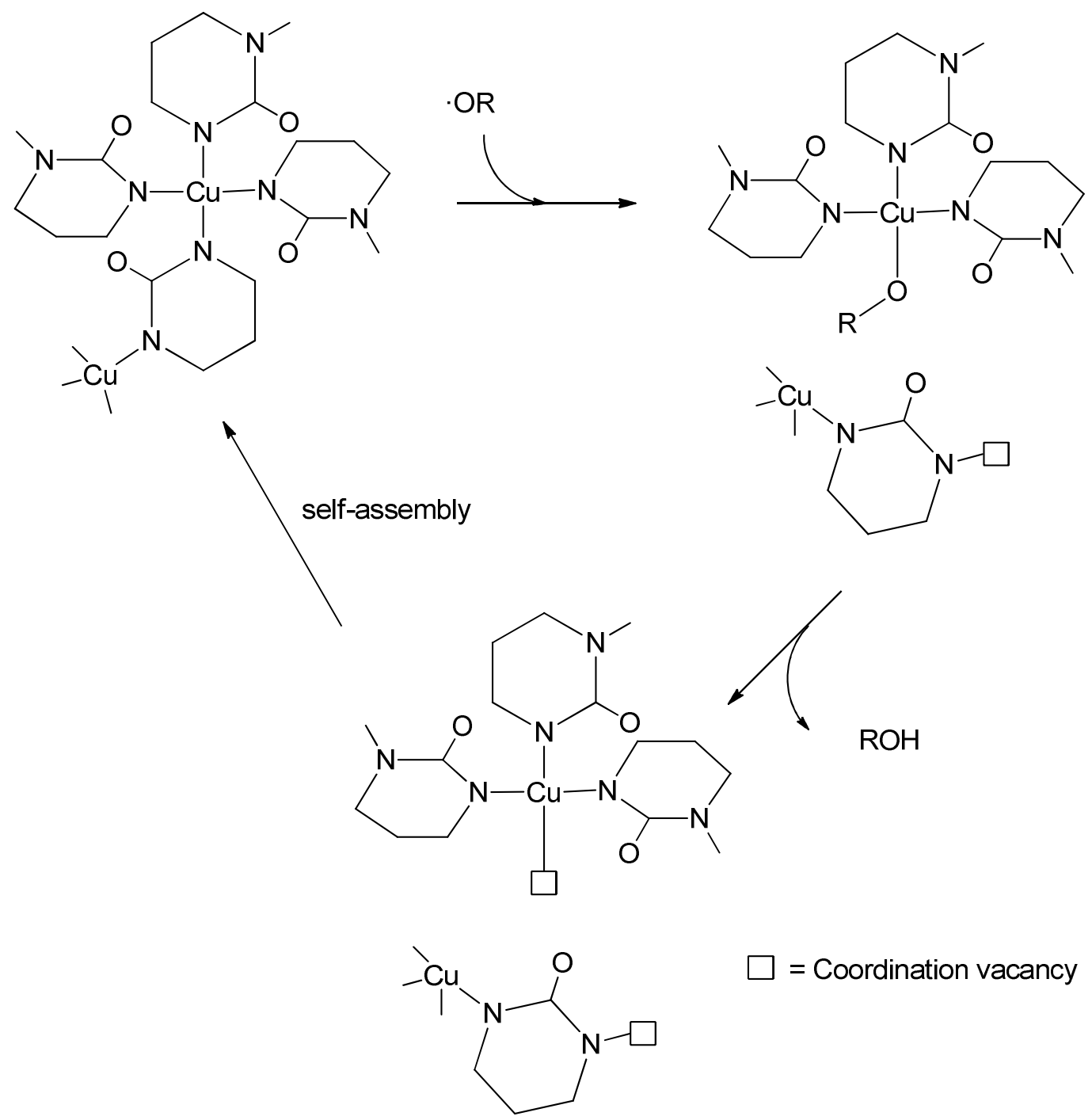


Scheme 3

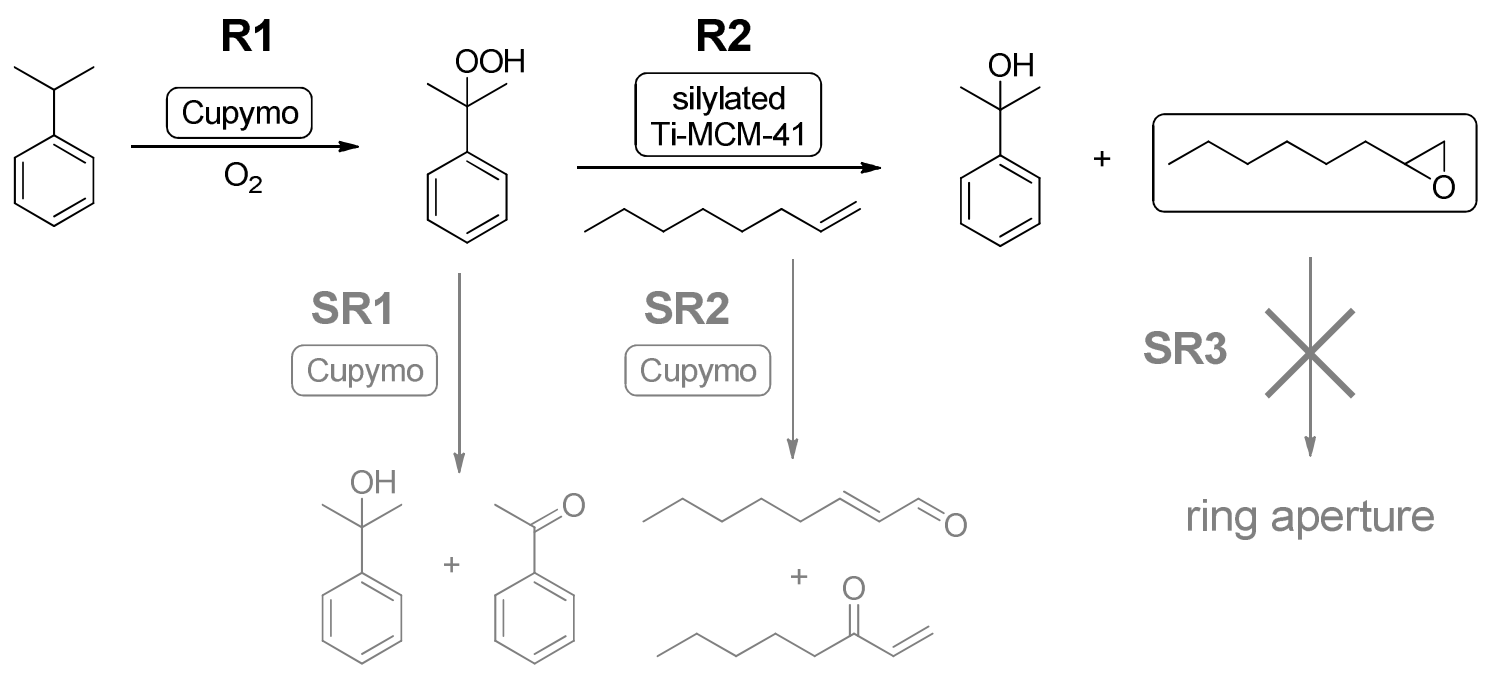

